\title{
Genetic variation in the cuticle-degrading protease activity of the entomopathogen Metarhizium flavoviride
}

\author{
Fabiana Gisele da Silva Pinto $^{1}$, Maria Helena Pelegrinelli Fungaro ${ }^{2}$, Josué Maldonado Ferreira ${ }^{2}$, Maria Cléria \\ Valadares-Inglis ${ }^{3}$ and Marcia Cristina Furlaneto ${ }^{1}$ \\ ${ }^{1}$ Departamento de Microbiologia, Universidade Estadual de Londrina, Londrina, PR, Brazil. \\ ${ }^{2}$ Departamento de Biologia Geral, Universidade Estadual de Londrina, Londrina, PR, Brazil. \\ ${ }^{3}$ Centro Nacional de Pesquisa de Recursos Genéticos e Biotecnologia (Cenargen/Embrapa), Brasília, DF, \\ Brazil.
}

\begin{abstract}
Extracellular proteases have been shown to be factors of virulence in fungal entomopathogenicity. We examined the production of the cuticle-degrading extracellular proteases chymoelastase (Pr1) and trypsin (Pr2) in isolates of the fungus Metarhizium flavoviride. Fungal growth was in a mineral medium (MM) containing nitrate, and in MM supplemented with either cuticle from Rhammatocerus schistocercoides or with the non-cuticular substrate casein. The substrates used for growth influenced the expression of both analyzed proteases, the highest protease activities of nearly all isolates having been observed in the medium containing insect cuticle, with more Pr1 than Pr2 being produced. There was a natural variability in the production of cuticle-degrading proteases among isolates, although this was less evident for Pr2. Our data support the hypothesis that the production of Pr1 on insect cuticle is a useful characteristic for the analysis of intraspecific variability of $M$. flavoviride isolates.
\end{abstract}

Key words: Metarhizium flavoviride, Rhammatocerus schistocercoides, chymoelastase (subtilisin) (Pr1), trypsin (Pr2).

Received: June 8, 1999 accepted: March 17, 2000.

\section{Introduction}

The South-American grasshopper, Rhammatocerus schistocercoides, is a major problem in Central Brazil, causing severe agricultural losses (Lecoq and Pierozzi, 1994). The entomopathogenic fungus Metarhizium flavoviride has been suggested as a biological control agent for locusts and grasshoppers (Prior et al., 1992), and it is known that some $M$. flavoviride isolates are highly virulent against $R$. schistocercoides (Magalhães et al., 1997). Fungal proteases are the enzymes most frequently considered critical in facilitating invasive mycosis of insects (Charnley and St. Leger, 1991), the studies on cuticle-degrading proteases in entomopathogenic fungi having mainly focused on Metarhizium anisopliae, which produces a chymoelastase (Pr1) (St. Leger et al., 1987a), a metalloprotease (St. Leger et al., 1994), a trypsin-like enzyme (Pr2) belonging to the serine protease group and a cysteine protease $(\operatorname{Pr} 4)$ (Cole et al., 1993).

The most extensively studied protease of $M$. anisopliae is $\operatorname{Pr} 1$, whose role in host invasion was clearly

Send correspondence to Marcia Cristina Furlaneto. Departamento de Microbiologia, Universidade Estadual de Londrina, Caixa Postal 6001, 86051-970 Londrina, PR, Brazil. E-mail: mcfurlan@ sercomtel.com.br. demonstrated by St. Leger et al. (1988). According to Charnley and St. Leger (1991), this enzyme provides the best understood model of the fungal entomopathogenicity determinant . Gillespie et al. (1998) found that the Pr1 protease from different isolates of Metarhizium hydrolyzes different types of insect cuticle to different degrees, although there was no correlation between Pr1 activity and the mean lethal time of the isolates in the desert locust (Schistocerca gregaria).

The role of the Pr2 protease in insect parasitism was not yet elucidated, although St. Leger et al. (1994) reported that Pr2 as well as the other cuticle-degrading proteases may complement each other in the splitting of peptide bonds in the insect cuticle. Results obtained by Gillespie et al. (1998) are consistent with a role of $\operatorname{Pr} 2$ in the induction or activation of $\operatorname{Pr} 1$, since $\operatorname{Pr} 2$ was detected before $\operatorname{Pr} 1$ in a culture containing ground locust cuticle. Both $\operatorname{Pr} 1$ and $\operatorname{Pr} 2$ are also produced by other entomogenous fungi, including Beauveria bassiana (St. Leger et al., 1987b; Gupta et al., 1992), Nomuraea rileyi, and Verticillim lecanii (St. Leger et al., 1987b).

The only study on the production of cuticle-degrading proteases by M. flavoviride used cuticle of the desert locust, S. gregaria (Gillespie et al., 1998). We compared 
the production of $\operatorname{Pr} 1$ and $\operatorname{Pr} 2$ in M. flavoviride isolates, after growth on $R$. schistocercoides cuticle, with to protease production on non-cuticular substrate (casein and nitrate).

\section{Materials and Methods}

\section{Organisms and culture conditions}

Seven isolates of Metarhizium flavoviride (syn. Metarhizium anisopliae var. acridum) were obtained as liquid nitrogen-stored stock cultures from the Cenargen/Embrapa-Brazil collection of entomopathogenic fungi: CG423, CG430, CG431, CG288 (isolated from Schistocerca pallens in Brazil), CG442 (ARSEF 3391; IMI 324673, isolated from Zonocerus elegans in Tanzania), CG441 (isolated from Ornithacris cavroisi in Nigeria), and CG291 (ARSEF 324, isolated from Austracnis guttulosa in Australia).

Conidia were obtained by harvesting sporulated spread plates of minimal medium (MM) (Pontecorvo et al., 1953), containing nitrate as nitrogen source, and MM supplemented with either $1.0 \%$ casein $(\mathrm{MM}+\mathrm{cas})$ or $0.5 \%$ $(\mathrm{w} / \mathrm{v})$ insect cuticle (MM+cut) prepared from adult Rhammatocerus schistocercoides using an aqueous solution of $1 \%$ potassium tetraborate (Andersen, 1980). The prepared cuticle was added to previously sterilized MM and autoclaved for $5 \mathrm{~min}$ at $115^{\circ} \mathrm{C}$. For enzyme production, conidia were inoculated into $100 \mathrm{~mL}$ of liquid $\mathrm{MM}+$ cas and $\mathrm{MM}+$ cut at a concentration of $1 \times 10^{7} \mathrm{~mL}^{-1}$ and incubated as shake cultures at $150 \mathrm{rpm}, 28{ }^{\circ} \mathrm{C}$, for $72 \mathrm{~h}$. The mycelia were harvested by filtration and the supernatants assayed for enzyme activity.

\section{Enzyme assays and protein determination}

In this paper, all $M$. flavoviride chymoelastase-like and trypsin-like activities are referred to as $\operatorname{Pr} 1$ and $\operatorname{Pr} 2$, respectively. Chymoelastase ( $\operatorname{Pr} 1)$ activity was assayed using succinyl-(alanine) $)_{2}$-proline-phenylalanine- $p$-nitroanilide, and trypsin $(\operatorname{Pr} 2)$ activity by using benzoyl-phenylalanine-valine-arginine- $p$-nitroanilide, as described by Gupta et al. (1992). Assays were performed with three replicates for each sample. Protein content was measured using Coomassie Brilliant Blue G-250 (Bradford, 1976).

\section{Statistical analyses}

Statistical analyses were performed using the Statistical Analysis System software (SAS Institute Inc., 1989). The experiment was set up as a randomized complete block design, with two replicates. The effect of treatment combinations (isolates and media) was assessed by factorial analysis. The variance analyses were followed by a comparison of the proteolytic activity means, using the Tukey test.

\section{Results and Discussion}

Chymoelastase (Pr1) activity was present in all the supernatants analyzed, and was highly expressed in the presence of insect cuticle (Figure 1). Isolate CG288 had the lowest activity, and isolate CG441 had the highest activity, about 27 times that of CG288 on the media tested.

All the isolates, with the exception of CG288, showed a significantly different $\operatorname{Pr} 1$ activity $(\mathrm{p}<0.01)$ as a function of the growth substrate (Table I), the enzyme activity being about 2 to 8 times higher in $\mathrm{MM}+$ cas and about 4 to 20 times higher in MM+cut than in MM. The high levels of Pr1 found in $\mathrm{MM}+$ cut cultures may be due to the induction of Pr1 by insect cuticle components, since Paterson et al. (1994) determined that the Pr1 activity of starved $M$. anisopliae mycelium is specifically induced by cuticle from $S$. gregaria.

Among the Brazilian isolates, there was a significant enhancement in the Pr1 activity of CG423 after growth on R. schistocercoides cuticle, which may be related to its high virulence against this grasshopper species (Magalhães et al., 1997), since quantitative differences in in vivo protease production between isolates can influence virulence (Gillespie et al., 1998).

Trypsin $(\operatorname{Pr} 2)$ was also produced by all isolates (Figure 2), but at lower levels than Pr1and with less variability between isolates than Pr1 (Table I). All isolates except CG288 and CG291 produced significantly different levels of trypsin $(p<0.01)$ as a function of the substrate used for growth (Table I), the highest production having been in $\mathrm{MM}+$ cut. Paterson et al. (1993) showed that M. anisopliae $\operatorname{Pr} 2$ is nonspecifically induced by any protein, if the fungus is starved of nitrogen, but not if starved of carbon in the presence of nitrogen. In our experiments with $\mathrm{MM}+$ cut, the Pr2 activity was only $29 \%$ (isolate CG442) and $24 \%$ (isolate CG423) of the $\operatorname{Pr} 1$ activity, similar results having been

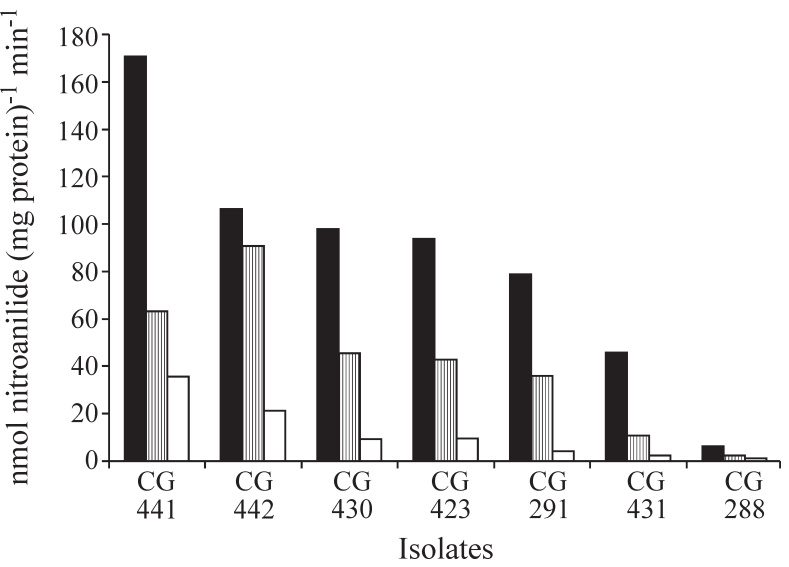

Figure 1 - Chymoelastase ( $\operatorname{Pr} 1)$ activity expressed as nmol nitroanilide released $\mathrm{mg}^{-1}$ protein $\mathrm{min}^{-1}$ from succinyl-(alanine) $)_{2}$-proline-phenylalanine-p-nitroanilide, in culture supernatants from Metarhizium flavoviride isolates grown in minimal medium $(\square)$ and minimal medium amended with casein $(1 \%)$ (vertical lines) or insect cuticle $(0.5 \%)(\square)$. The results are from two experiments with three replicates for each sample. 
Table I - Mean values of chymoelastase ( $\operatorname{Pr} 1)$ and trypsin $(\operatorname{Pr} 2)$ activities from Metarhizium flavoviride isolates grown in minimal medium plus cuticle $(\mathrm{MM}+$ cut), minimal medium plus casein $(\mathrm{MM}+\mathrm{cas})$, and minimal medium $(\mathrm{MM})$, respectively. The results are from two experiments with three replicates for each sample.

\begin{tabular}{|c|c|c|c|c|c|c|c|}
\hline \multirow{3}{*}{ Medium } & \multicolumn{7}{|c|}{ M. flavoviride isolate } \\
\hline & \multicolumn{7}{|c|}{$\operatorname{Pr} 1$ activity } \\
\hline & CG441 & CG442 & CG430 & CG423 & CG291 & CG431 & CG288 \\
\hline $\mathrm{MM}+\mathrm{cut}$ & $170.70 \mathrm{aA}$ & $106.40 \mathrm{aB}$ & $97.89 \mathrm{aC}$ & $93.72 \mathrm{aC}$ & $78.72 \mathrm{aD}$ & $45.69 \mathrm{aE}$ & $6.30 \mathrm{aF}$ \\
\hline $\mathrm{MM}+\mathrm{cas}$ & $63.34 \mathrm{bB}$ & $90.62 \mathrm{bA}$ & $45.52 \mathrm{bC}$ & $42.95 \mathrm{bCD}$ & $35.99 \mathrm{bD}$ & $10.68 \mathrm{bE}$ & $2.32 \mathrm{aF}$ \\
\hline \multirow[t]{3}{*}{ MM } & $35.56 \mathrm{cA}$ & $21.36 \mathrm{cB}$ & $9.40 \mathrm{cC}$ & $9.47 \mathrm{cC}$ & $4.25 \mathrm{cCD}$ & $4.25 \mathrm{cCD}$ & $1.06 \mathrm{aD}$ \\
\hline & \multicolumn{7}{|c|}{$\operatorname{Pr} 2$ activity } \\
\hline & CG442 & CG441 & CG288 & CG291 & CG431 & CG430 & CG423 \\
\hline $\mathrm{MM}+\mathrm{cut}$ & $31.29 \mathrm{aA}$ & $24.15 \mathrm{aB}$ & $22.05 \mathrm{aB}$ & $18.47 \mathrm{aC}$ & $22.13 \mathrm{aBC}$ & $21.20 \mathrm{aBC}$ & $22.64 \mathrm{aBC}$ \\
\hline $\mathrm{MM}+\mathrm{cas}$ & $25.27 \mathrm{bA}$ & $15.98 \mathrm{cBC}$ & $20.07 \mathrm{aB}$ & $20.72 \mathrm{aAB}$ & $15.84 \mathrm{bBC}$ & $15.66 \mathrm{bBC}$ & $11.55 \mathrm{bC}$ \\
\hline MM & $12.40 \mathrm{cB}$ & $19.65 \mathrm{bA}$ & $6.43 \mathrm{bC}$ & $1.22 \mathrm{bD}$ & $1.95 \mathrm{cCD}$ & $1.52 \mathrm{cD}$ & $1.95 \mathrm{cCD}$ \\
\hline
\end{tabular}

Different letters represent a significant difference $(\mathrm{p}<0.05)$ according to Tukey's test. Lower case letters indicate significant differences within a column, and capital letters within a row.

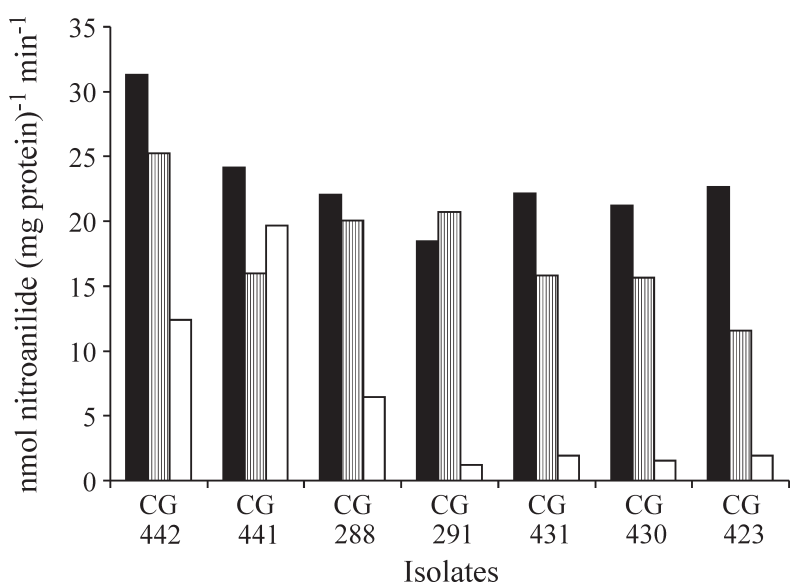

Figure 2 - Trypsin (Pr2) activity expressed as nmol nitroanilide released $\mathrm{mg}^{-1}$ protein $\min ^{-1}$ from benzoyl-phenylalanine-valine-arginine- $p$-nitroanilide, in culture supernatants from Metarhizium flavoviride isolates grown in minimal medium $(\square)$ and minimal medium amended with casein (1\%) (vertical lines) or insect cuticle $(0.5 \%)(\square)$. The results are from two experiments with three replicates for each sample.

observed for cuticle-degrading proteases produced by $M$. anisopliae against $S$. gregaria (Cole et al., 1993).

In our study, the substrates used for growth significantly influenced the expression of $\operatorname{Pr} 1$ and $\operatorname{Pr} 2$, except in isolate CG288 (Table I).We found a natural variability in the production of insect cuticle-degrading proteases among M. flavoviride isolates. Strain variability has also been observed in the production of proteases in M. anisopliae (St. Leger et al., 1986; Gillespie et al., 1998) and in B. bassiana (Gupta et al., 1992), while Leal et al. (1997) demonstrated significant variations in Pr1 sequences among strains of entomopathogenic fungi. It has also been described that $M$. anisopliae proteases comprise multiple isoforms (St. Leger et al., 1994).
A consistent pattern of Pr1 expression was apparent among isolates, with all isolates except CG423 and CG430 producing statistically different levels of Pr1 on cuticle, which gave a $100 \%$ homology on RAPD analysis (Martins, 1998). The production of $\operatorname{Pr} 1$ in a culture containing $R$. schistocercoides cuticle may be useful to analyze strain variability of $M$. flavoviride and related entomopathogenic fungi. Leal et al. (1997) used the PCR product derived from the $M$. anisopliae $\operatorname{Pr} 1$ gene to differentiate between many Metarhizium strains. Fungal strain variability in Pr1 production may be directly related to variability in virulence, because the regulation of the Pr1 gene expression may determine the capacity of the fungus to cause insect disease (St. Leger et al., 1988).

\section{Acknowledgement}

This work received financial support from $\mathrm{CNPq}$ and CPG/UEL. F.G.S.P. holds a CAPES fellowship.

\section{References}

Andersen SO (1980) Cuticular sclerotization. In: Cuticle Techniques in Arthropods. (Miller, TA, ed.) Springer-Verlag, New York, pp 185-217.

Bradford MM (1976) A rapid and sensitive method for the quantitation of microgram quantities of protein utilizing the principle of protein-dye binding. Anal. Biochem. 72:248-254.

Charnley AK and St. Leger RJ (1991) The role of cuticle degrading enzymes in fungal pathogenesis of insects. In: The fungal spore and disease initiation in plants and animals. Plenum Publishing Co., New York. pp 267-286.

Cole SCJ, Charnley AK and Cooper RM (1993) Purification and partial characterization of a novel trypsin-like cysteine protease from Metarhizium anisopliae. FEMS Microbiol. Lett. 113:189-196.

Gillespie JP, Bateman R and Charnley AK (1998) Role of cuticle-degrading proteases in the virulence of Metarhizium spp. 
for the desert locust, Schistocerca gregaria. J. Invertebr. Pathol. 71:128-137.

Gupta SC, Leathers TD, El-Sayed GN and Ignoffo CM (1992) Insect cuticle-degrading enzymes from the entomogenous fungus Beauveria bassiana. Exp. Mycol. 16:132-137.

Leal SCM, Bertioli DJ, Butt TM, Carder JH, Burrows PR and Peberdy JF (1997) Amplification and restriction endonuclease digestion of the Pr1 gene for the detection and characterization of Metarhizium strains. Mycol. Res. 101:257-265.

Lecoq M and Pierozzi Jr I (1994) Rhammatocerus schistocercoides (Rehn, 1906), criquet ravageur des Etats du Mato Grosso e du Rondonia, Brésil. Essai de synthèse bibliographique. CIRAD-PRIFAS, Montpellier, France.

Magalhães BP, Faria M, Tigano MS and Sobral BWS (1997) Characterization and virulence of a Brazilian isolate of Metarhizium flavoviride Gams and Rozsypal (Hyphomycetes). Mem. Entomol. Soc. Can. 171:313-321.

Martins MK (1998) RNA dupla fita (dsRNA) em Metarhizium flavoviride. Master's thesis, Universidade Estadual de Londrina, Londrina, Brasil.

Paterson IC, Charnley AK, Cooper RM and Clarkson JM (1993) Regulation of production of a trypsin-like protease by the insect pathogenic fungus Metarhizium anisopliae. FEMS Microbiol. Lett. 109:323-328.

Paterson IC, Charnley AK, Cooper RM and Clarkson JM (1994) Specific induction of a cuticle-degrading protease of the in- sect pathogenic fungus Metarhizium anisopliae. Microbiology 140:185-189.

Pontecorvo G, Roper JA, Hemons LM, MacDonald KD and Bufton AWJ (1953) The genetics of Aspergillus nidulans. Adv.Genet. 5:141-238.

Prior C, Lomer CJ, Herren H, Paraso A, Kooyman C and Smit JJ (1992) The IIBC/IITA/DFPV collaborative research programme on the biological control of locusts and grasshoppers. In: Biological Control of Locusts and Grasshoppers. CAB International, Wallingford. pp 8-18.

St. Leger RJ, Bidochka MJ and Roberts DW (1994) Isoforms of the cuticle-degrading Pr1 proteinase and production of a metalloproteinase by Metarhizium anisopliae. Arch. Biochem. Biophys. 313:1-7.

St. Leger RJ, Charnley AK and Cooper RM (1986) Cuticledegrading enzymes of entomopathogenic fungi: synthesis in culture on cuticle. J. Invertebr. Pathol. 48:85-95.

St. Leger RJ, Charnley AK and Cooper RM (1987a) Characterization of cuticle degrading proteases produced by the entomopathogen Metarhizium anisopliae. Arch. Biochem. Biophys. 253:221-232.

St. Leger RJ, Cooper RM and Charnley AK (1987b) Distribution of chymoelastases and trypsin-like enzymes in five species of entomopathogenic Deuteromycetes. Arch. Biochem. Biophys. 258:121-131.

St. Leger RJ, Durrands PK, Charnley AK and Cooper RM (1988) Role of extracellular chymoelastase in the virulence of Metarhizium anisopliae for Manduca sexta. J. Invertebr. Pathol. 52:285-293. 